\title{
The neuropeptidome of the Crown-of-Thorns Starfish, Acanthaster planci
}

Meaghan K. Smith ${ }^{1}$, Tianfang Wang ${ }^{1}$, Saowaros Suwansa-ard ${ }^{1}$, Cherie A. Motti ${ }^{2}$, Abigail Elizur $^{1}$, Min Zhao ${ }^{1}$, Matthew L. Rowe ${ }^{3}$, Michael R. Hall ${ }^{2}$, Maurice R. Elphick ${ }^{3}$, Scott F. Cummins ${ }^{1, *}$

${ }^{1}$ Genecology Research Centre, University of the Sunshine Coast, Maroochydore DC, Queensland 4558, Australia; ${ }^{2}$ Australian Institute of Marine Science (AIMS), Cape Ferguson, Townsville Queensland 4810, Australia; ${ }^{3}$ School of Biological and Chemical Sciences, Queen Mary University of London.

* Corresponding author: Scott F. Cummins, Email-scummins@usc.edu.au

\begin{abstract}
Outbreaks of Crown-of-Thorns starfish (COTS; Acanthaster planci) are a major cause of destruction of coral communities on the Australian Great Barrier Reef. Whilst factors relating to population explosions and the social interactions of COTS have been well studied, little is known about the neural mechanisms underlying COTS physiology and behaviour. One of the major classes of chemical messengers that regulate physiological and behavioural processes in animals are the neuropeptides. Here, we have analysed COTS genome and transcriptome sequence data to identify neuropeptide precursor proteins in this species. A total of 48 neuropeptide precursors were identified, including homologs of neuropeptides that are evolutionarily conserved throughout the Bilateria, and others that are novel. Proteomic mass spectrometry was employed to confirm the presence of neuropeptides in extracts of radial nerve cords. These transcriptomic and proteomic resources provide a foundation for functional studies that will enable a better understanding of COTS physiology and behaviour, and may facilitate development of novel population biocontrol methods.
\end{abstract}


Key words: Crown-of-Thorns starfish, neuropeptide, echinoderm, bioinformatics

\section{Significance}

The Crown-of-Thorns Starfish (COTS) is one of the primary factors leading to coral loss on the Great Barrier Reef, Australia. The combined genomic, transcriptomic and proteomic findings of this study reveal the COTS neuropeptidome, including homologs of known neuropeptides and novel putative neuropeptides. This represents the most comprehensive neuropeptidome for an echinoderm, contributing to an evolving knowledge of COTS molecular neurobiology that may assist towards the development of biocontrol methods.

\section{Introduction}

The Crown-of-Thorns Starfish (COTS; Phylum Echinodermata, Acanthaster planci) is a mobile corallivore that is capable of consuming up to ten square meters of hard corals per year. When COTS population numbers are high, there is a devastating impact on the Great Barrier Reef (GBR) and reefs of the Indo-Pacific region $[1,2]$. With the GBR recognized as a heritage site and natural wonder of the world, its ecological significance along with contributions to the revenue of the Australian economy means the preservation, sustainability and health of the GBR is of high importance $[3,4]$.

COTS research, including ecological studies, has primarily focused on understanding behavioural traits, such as aggregation leading to spawning, as well as the environmental influences that contribute to population fluctuations [4]. Thus far, no comprehensive study has been carried out to explore the neural molecular mechanisms that regulate COTS physiology and behaviour, yet there has been growing interest [5]. The main components of the COTS nervous system are the radial nerve cords, which extend along the entire oral side of each arm, and which are linked by a circumoral nerve ring in the central disk region [6-8]. Neural 
signalling systems may include various common eumetazoan cellular signalling components, including amino acids and their derivatives (e.g. glutamate, GABA), amines (e.g. norepinephrine, serotonin), lipids (e.g. endocannabinoids) and gases (e.g. nitric oxide) [9]. Also, neuropeptides that are derived from precursor proteins are one of the most diverse classes of neuronal signalling molecules [10]. Single precursor proteins may give rise to single or multiple bioactive peptides cleaved at flanking monobasic or dibasic sites, whilst also undergoing posttranslational modifications (e.g. C-terminal amidation).

Neuropeptides play important roles in the control and regulation of many physiological processes and behaviours. For example, relaxin-like gonad-stimulating peptide (RGP) was identified as the neuropeptide that controls final gamete maturation in starfish [11]. Originally named gonad-stimulating substance (GSS), RGP was isolated from the radial nerve cords and triggered spawning in the starfish Asterias forbesi $[12,13]$. Interestingly, in sea cucumbers spawning is triggered by a different type of neuropeptide - the pentapeptide NGIWYamide, which also acts as a muscle contractant $[14,15]$. A homolog of NGIWYamide identified in the starfish Asterias rubens is the neuropeptide NGFFYamide, which is implicated in neural mechanisms controlling the extraoral feeding behaviour of starfish [16]. Thus, NGFFYamide causes contraction and retraction of the cardiac stomach in $A$. rubens, indicating a potential physiological role in terminating feeding activity. Conversely, the SALMFamide neuropeptides $\mathrm{S} 1$ and S2 trigger cardiac stomach relaxation and eversion in $A$. rubens, indicating potential physiological roles in initiation of feeding activity in starfish [17-19]. More recently another starfish neuropeptide that acts as muscle relaxant has been identified and named starfish myorelaxant peptide (SMP). SMP was isolated from Patiria pectinifera and belongs to a bilaterian family of neuropeptides that include molluscan pedal peptides and arthropodan orcokinins [20]. 
In silico analysis of echinoderm neuropeptides from genomic and transcriptomic datasets began with the sequencing of the purple sea urchin (Strongylocentrotus purpuratus) genome [21]. In excess of twenty neuropeptide precursor genes have so far been identified in S. purpuratus $[22,23]$. Subsequently, in silico analysis of transcriptome sequence data has enabled identification of related neuropeptide precursors in other echinoderms, including the sea cucumber Apostichopus japonicus [24] and, most relevant to the current study, the starfish A. rubens $[16,25]$. The release of the COTS draft genome, the first for an asteroid, and various tissue transcriptomes [26] provides an opportunity to explore in greater depth COTS neuropeptides at both the gene and peptide levels.

To gain a deeper understanding of the molecular mechanisms that regulate COTS physiology and behaviour, here we performed an in silico analysis of the COTS genome to identify neuropeptide precursors. Furthermore, the presence of neuropeptides derived from precursor proteins was confirmed by proteomic mass spectral interrogation of COTS radial nerve cord extracts. By advancing understanding of this aspect of COTS biology, we provide the foundations for further exploration of the neurobiology and physiology of COTS, which may facilitate development of biocontrol strategies.

\section{Methods}

\section{In silico identification of neuropeptide precursors in COTS (Acanthaster planci)}

To identify neuropeptide precursor sequences, the COTS genome sequence dataset (http://marinegenomics.oist.jp/cots) was downloaded and imported into the CLC Genomics Workbench (v7.0; Finlandsgade, Dk). Sequences of neuropeptide precursors identified previously in other echinoderm species were used as the input for sequence-based similarity searches (BLASTp). These included neuropeptide precursor proteins from S. purpuratus [27], 
A. japonicus [24] and A. rubens [25]. In parallel, open reading frames retrieved from BLAST searches were screened for the presence of signal peptide sequences (SignalP 4.0) [28], transmembrane domains (TMHMM Server v. 2.0) [29] and for neuropeptide features such as recurrent KK; KR; RK; RR motif cleavage sites (Neuropred) [30, 31]. To enable identification of putative novel neuropeptide precursors, this method was also applied to open reading frames for which no previously identified neuropeptide precursor was matched in BLAST searches. Multiple sequence alignments for neuropeptides were created with the Molecular Evolutionary Genetics Analysis (MEGA) software version 7.0 [32]. Multiple sequence alignment schematics were generated using LaTeX's TeXShade packages [33]. Schematic diagrams of protein domain structures were prepared using Domain Graph (DOG, version 2.0) software. For relative expression analysis, transcriptome data for each of the tissues represented in http://marinegenomics.oist.jp/cots was downloaded and heatmaps constructed using R (version 3.1.1) (https://www.r-project.org/) based on Z-score values using the scale function.

\section{Animals for radial nerve collection and peptide isolation}

COTS were collected from individual reefs in regions of the Great Barrier Reef, Cairns, Queensland, by the Association of Marine Park Tourism Operator divers during routine COTS removal dives, then transferred to either the Under Water World SeaLife Aquarium (Mooloolaba) or the AIMS SeaSIM facility (Townsville). At least 6 animals were housed at any given time in protein-skimmed saltwater aquariums for durations varying from two days to six months and received a minimal diet of fish pieces and pellets or seaweed. This diet may not be optimal for coral-eating starfish. but we have no evidence of an impact on the outcomes of this study. For experiments, gender and sexual maturity of COTS were determined by microscopic examination of the gonad tissue for the presence of oocytes or sperm, with the 
maturation stage of oocytes determined based on histology reported in the Northern Pacific Seastar, Asterias amurensis [12]. No ethics approvals were required for this study because research on starfish is not subject to ethics regulation.

\section{Identification of neuropeptides in COTS radial nerve extracts using mass spectrometry (MS)}

COTS arms were amputated, dissected and the radial nerve removed. Dissected radial nerves were viewed and photographed with a light microscope (BX51; Olympus) equipped with a camera (UC50; Olympus). An outline of the workflow used to identify COTS neuropeptides from extracts is shown in Figure S1. Adult COTS radial nerve (pooled male and female) tissues were collected from animals $(n=4)$ and the peptides extracted from homogenized tissue using acidified methanol (Sigma-Aldrich; methanol/acidic acid/milliQ water, 90:9:1). Samples were pooled from males and females because comparison of expression levels in males and females was beyond the scope of this study. To purify peptides, extracts were filtered through an Ultrafree-MC, $\mathrm{HV} 0.45 \mu \mathrm{m}$ pore-size sterile filter (Millipore Corporation, Billerica, MA, USA) then centrifuged through an Amicon Ultra-4 centrifugal filter unit $\left(10 \mathrm{kDa}\right.$; Millipore Corporation, Billerica, MA, USA) at $4000 \times g$ for $40 \min \left(4^{\circ} \mathrm{C}\right)$. The eluent was collected and lyophilized before further analysis. Lyophilized peptide samples were dissolved in $0.1 \%$ trifluoroacetic acid (TFA) in milliQ water, then separated by reverse phase high-performance liquid chromatography (RP-HPLC) using a Zorbax 50 x 0.5 mm C18 column (Agilent). The mobile phases for reverse phase separation were $0.1 \%$ TFA in MilliQ water (solvent A) and $0.1 \%$ TFA in acetonitrile (solvent B). A linear gradient from $0 \%$ to $60 \%$ of solvent $\mathrm{B}$ at flow rate of $1 \mathrm{ml} / \mathrm{min}$ over $60 \mathrm{~min}$ was used. HPLC fractions ( $5 \mathrm{~min} /$ fraction) were collected for LC-MS/MS analysis on a Shimadzu Prominance Nano HPLC (Japan) coupled to a Triple TOF 5600 MS (ABSCIEX, Canada) equipped with a nano electrospray ion source. A 
$6 \mu 1$ aliquot of each HPLC fraction was injected onto a $50 \mathrm{~mm} \times 300 \mu \mathrm{m}$ C18 trap column (Agilent Technologies, Australia) and de-salted for 5 min using $0.1 \%$ formic acid (aq) at 30 $\mu 1 / \mathrm{min}$. The trap column was then placed in-line with a $150 \mathrm{~mm}$ x $75 \mu \mathrm{m} 300 \mathrm{SBC} 18,3.5 \mu \mathrm{m}$ nano HPLC column (Agilent Technologies, Australia) for LC-MS analysis. Peptides were eluted at a flow rate of $300 \mathrm{~nL} / \mathrm{min}$ using a linear gradient of $1-40 \%$ solvent $\mathrm{B}$ (solvent $\mathrm{A}=$ 0.1\% formic acid in milliQ water; solvent $\mathrm{B}=$ acetonitrile:0.1\% formic acid (aq) 90:10) over 35 min followed by a steeper gradient from $40 \%$ to $80 \%$ solvent B over 5 min. The gradient was held at $80 \%$ solvent $\mathrm{B}$ for 5 min to wash the column and returned to $1 \%$ solvent $\mathrm{B}$ for equilibration prior to the next sample injection. The ionspray voltage was set to $2400 \mathrm{~V}$, declustering potential (DP) 100V, curtain gas flow 25, nebuliser gas 1 (GS1) 12 and interface heater at $150^{\circ} \mathrm{C}$. The mass spectrometer acquired $500 \mathrm{~ms}$ full scan TOF-MS data followed by 20 x 50 ms full scan product ion data in an Information Dependent Acquisition (IDA) mode. Full scan TOF-MS data was acquired over the mass range $350-1800 \mathrm{~m} / \mathrm{z}$ and for product ion MS/MS 100-1800 m/z. Ions observed in the TOF-MS scan exceeding a threshold of 100 counts and a charge state of +2 to +5 were set to trigger the acquisition of product ion MS/MS spectra of the resultant 20 most intense ions. The data was acquired and processed using Analyst TF

\subsection{1 software (ABSCIEX, Canada).}

Peptides were analysed using PEAKS v7.0 (BSI, Canada) against the protein database built from the COTS transcriptomes and genome data [26]. Search parameters were as follows: no enzyme was used; and variable modifications included methionine oxidation, conversion of glutamine to pyroglutamic acid, deamidation of asparagine and C-terminal amidation. Peptides that were identified by MS, yet did not hold a match to documented neuropeptides were screened for the presence of signal sequences, cleavage sites and lack of transmembrane domains as described above and were deemed to be novel neuropeptides. 


\section{Results}

\section{Overview of COTS neuropeptide precursor transcripts and proteomics of radial nerve}

A total of 48 neuropeptide precursors were discovered based on our analysis of COTS genome/transcriptome data, with 38 of these being characterised previously in A. rubens and/or in other echinoderms $[24,25,27]$ and the additional 10 being precursors of putative novel neuropeptides (Table 1 and File S1). Initial screening of genome sequence data did not identify all neuropeptide precursors, but subsequent analysis of transcriptome data enabled gene identification (e.g. the gonadotropin-releasing hormone (GnRH)-type precursor).

To further investigate the presence in radial nerve tissue of neuropeptides derived from the 48 precursor proteins, peptides were isolated from radial nerve of adult COTS (pooled male and female; Fig. 1A) and then fractionated by RP-HPLC. RP-HPLC chromatograms at UV 210 nm showed the presence of numerous biomolecules (Fig. 1B), from which 5 min fractions were collected for subsequent MS analysis. Proteomic data has been deposited into the PRIDE database with accession number PXD005837. MS analysis of COTS radial nerve extracts confirmed the presence of peptides derived from 25 of the 48 neuropeptide precursors (Table 1 and File S1). These included 9 of the 10 putative novel neuropeptide precursor proteins that have been designated: ApNP26, ApNP27 (Acanthaster planci Neuropeptide Precursor_X), and so forth, following sequential nomenclature of novel echinoderm neuropeptides identified to date $[25,27]$. The putative novel neuropeptide precursor ApNP28 was identified in silico based on features consistent with neuropeptide precursors, but peptide fragments of this protein were not detected by MS. In conclusion, a total of 48 neuropeptide precursors have been identified, 
10 of which are regarded as being novel. A total of 25 of these neuropeptide precursors are supported by MS proteomic analysis.

Relative expression of neuropeptide genes (based on Z-scores) within various COTS tissues, including radial nerve cords, is shown in Figure 2. There is overall high expression present within the radial nerve cords for both male and female, relative to other tissues sampled. Only the mouth, spine and sensory tentacles had expression levels of several neuropeptide precursors that matched the radial nerve cords or had a higher relative expression.

\section{COTS homologs of neuropeptides that have been characterised previously in other} echinoderms

Neuropeptide precursors of RGP, SALMFamides, NGIWYamide, asterotocin (vasopressin/oxytocin-like; VP/OT) and SMP were selected for more detailed analysis as homologs of these neuropeptides have been functionally characterised previously in starfish or other echinoderms $[18,25,34]$. The COTS precursors of these neuropeptides showed a general organization consistent with homologous neuropeptide precursors in A. rubens or other echinoderms, including the existence of an $\mathrm{N}$-terminal signal sequence, multiple cleavage sites, bioactive regions, repetitive domains and conserved cysteines (if present) (Fig. 3). Experimental studies are now required to investigate the physiological roles of these and other neuropeptides in COTS.

Relative expression analysis (Fig. 2) revealed that some neuropeptide precursor genes, including RGP and glycoprotein hormone (GPH)-beta-5(-c) were sparsely expressed in the radial nerve cord but were highly expressed in COTS spines. Even so, gene transcripts for these neuropeptides are still present within the radial nerve cord (Table 1). The COTS RGP (-b) identified in this study is a 124 amino acid precursor with two highly conserved peptide chains, 
A and B chains, similar to RGPs identified in other starfish species (Fig. 4A). The COTS RGP

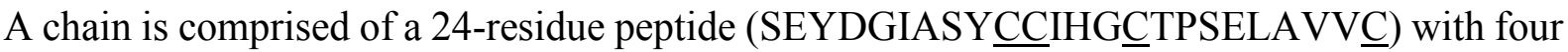
conserved cysteines, while the $\mathrm{B}$ chain is comprised of a 19-residue peptide (EKFCDDNFHLAVYQTCESTH) containing two conserved cysteines. This RGP (COTS $R G P b$ ) varies from a previously described COTS RGP (COTS $R G P a$ ) [11]. The RGPb precursor has 124 amino acids in contrast to the 116 amino acid precursor of RGPa, and includes three and eight amino acid differences in the $\mathrm{A}$ and $\mathrm{B}$ chain, respectively. $\mathrm{A}$ phylogenetic analysis of all RGP precursors shows that the COTS RGPb forms a separate branch (Fig. 4B).

Eleven neuropeptide precursor-like proteins were identified in COTS that exhibit homology to neuropeptide precursors first described in A. rubens [25]; three were further confirmed by MS (File S1). The ApNP11, ApNP15a, ApNP15b and ApNP18 were named on account of similarity to the A. rubens neuropeptides ArNP11, ArNP15a, ArNP15b and ArNP18, which were themselves named based on similarity with putative neuropeptides first discovered in the purple sea urchin S. purpuratus and thus follow suite in nomenclature. Others, such as ApNP22, ApNP23-like and ApNP25 were named based only on observed similarity to $A$. rubens neuropeptides. No COTS homolog was identified for ArNp21 or ArNP24.

\section{Characterisation of novel neuropeptides in COTS}

The 10 novel neuropeptide precursors identified here in COTS are named ApNP26 sequentially through to ApNP35, following a system of nomenclature used previously for echinoderm neuropeptide precursors [27]. Homologous proteins with significant similarity $(<$ e-value $10^{-3}$ ) to the 10 novel COTS neuropeptide precursors were identified in the starfish Patiria miniata, based on analysis of genome sequence data from this species 
(www.echinobase.org) [35] (File S2). Based on MS analysis of the radial nerve, the strongest evidence that putative neuropeptides are derived from the novel neuropeptide precursors was obtained for ApNP33-35 (Fig. 5 and File S1). ApNP33 contains multiple dibasic cleavage sites and MS analysis shows the presence of two different peptides. ApNP34 gene expression is also relatively abundant in the mouth and spine tissues. Its 117-residue precursor contains two dibasic cleavage sites from which the two MS peptides were identified: DRWTYPAVPPRETR and a shorter fragment of this peptide (DRWTYPAVPPR). The ApNP35 precursor had numerous MS peptide matches specific to the region between the signal peptide and dibasic cleavage site $\mathrm{R}_{40} \mathrm{R}$. The predicted 17 amino acid peptide derived from this precursor shows no similarity to any known neuropeptide previously reported.

\section{Discussion}

Characterisation of neural signalling in the COTS is necessary to understand the molecular mechanisms that regulate their physiology and behaviour. In this study, 48 COTS neuropeptide precursors have been identified through genomic and proteomic techniques. As echinoderms are deuterostomian invertebrates, echinoderm neuropeptides exhibit homology with neuropeptides in both vertebrates and protostomian invertebrates, which can facilitate reconstruction of neuropeptide evolution [25, 36, 37]. For example, identification of neuropeptides that act as ligands for a GnRH-type receptor and corazonin-type receptor has revealed that the evolutionary origin of paralogous GnRH-type and corazonin-type signalling can be traced back to the common ancestor of protostomes and deuterostomes [37] and here precursors of GnRH-type and corazonin-type neuropeptides have been identified in COTS. However, some neuropeptide families may be unique to echinoderms or specifically starfish. 
For example, precursors of SALMFamides and AN peptides have thus far only been identified in echinoderms, including COTS as reported here. Furthermore, here we report the identification in COTS of 10 putative novel neuropeptide precursors, for which homologs were also found in Patiria miniata based on analysis of genome sequence data [35]. Mass spectral analysis of COTS radial nerve extracts provided evidence that these precursors are subject to proteolytic processing. However, further experimental studies are required to investigate the functional significance of these proteins as precursors of putative neuropeptides. Furthermore, if these proteins are unique to starfish, this may provide a basis for targeted biocontrol strategies.

Previous studies have functionally characterised some neuropeptides in starfish or echinoderms, which provides a basis for discussion of potential physiological roles of some of the neuropeptides identified here COTS. These include SALMFamides, which have been shown to act as general muscle relaxants in echinoderms, and in starfish there is evidence that SALMFamides may mediate stomach eversion during feeding behaviour [38, 39]. Conversely, the neuropeptide NGFFYamide has been shown to act as muscle contractant that triggers cardiac stomach retraction in starfish [16]. NGFFYamide belongs to a family of neuropeptides in deuterostomian invertebrates that have a consensus 'Asn-Gly' motif and hence these are referred to as NG peptides [34]. Identification of the receptor for the sea urchin NG peptide NGFFFamide has revealed that this family of neuropeptides are orthologs of neuropeptide-S (NPS) in vertebrates and crustacean cardioactive peptides (CCAPs) in protostomian invertebrates [36]. An unusual feature of NG peptide precursors, including the COTS NGFFYamide precursor, is the presence of a C-terminal neurophysin domain, which reflects a common evolutionary ancestry with vasopressin/oxytocin (VP/OT)-type neuropeptide precursors that also have a neurophysin domain [36]. Here a precursor of VP/OT-type neuropeptide has been identified in COTS that is identical to a VP/OT-type neuropeptide named 
asterotocin that was identified recently in A. rubens [25]. Interestingly, asterotocin displays atypical residues in positions 2, 3 and 8 , which may be unique to starfish [25]. Nothing is currently known about the physiological roles of asterotocin in starfish, however it has been shown that a VP/OT-type neuropeptide in sea urchins, named echinotocin, causes contraction of in vitro preparations of tube feet and oesophagus [23]. Here we have found that the asterotocin precursor is widely expressed in COTS tissues (Table 1), suggesting that asterotocin may be involved in regulation of a variety of physiological processes in starfish. Another starfish neuropeptide that has been functionally characterised recently is starfish myorelaxant peptide (SMP), which was identified in Patiria pectinifera. SMP is derived from a precursor of a family of neuropeptides that belong the bilaterian pedal peptide/orcokinin (PP/OK) neuropeptide family [20]. Here we have identified a homolog of the SMP precursor in COTS, which provides a basis for functional characterisation of SMP-type peptides in this species. Furthermore, we also identified a COTS homolog of a second PP/OK-type neuropeptide precursor that was discovered recently in A. rubens [25]. Functional characterisation of SALMFamides, NG peptides, VP/OT-type and PP/OK-type neuropeptides as myoactive peptides in starfish or other echinoderms provide a basis for investigation of the physiological roles of COTS homologs and development of novel biocontrol strategies.

With respect to the reproductive biology of starfish, RGP (formerly GSS) has been identified as a gonadotropic peptide in $P$. pectinifera and subsequently in other starfish species [40-42]. RGP belongs to the relaxin-like peptide family that shares a common ancestral gene with the insulin and insulin-like growth factor families [43-47]. In starfish, RGP acts upon Gprotein coupled receptors that are only expressed in fully mature oocytes [44] stimulating the release of 1-methyladenine (1-MeAde) from follicle cells to induce spawning [44-46]. RGP alone, however, is unable to induce the entire chemical cascade that activates immature follicle 
cells but is considered to be a major factor in the regulation of starfish reproductive physiology [43-46]. Analysis of COTS transcriptome data reveals that RGP is expressed in the radial nerve cords, but interestingly RGP transcripts are more abundant in spines and tube foot podia. Recent analysis of RGP expression in A. rubens has revealed that it is expressed by cells located in the body wall epithelium associated with the sensory terminal tentacle located at the tips of each arm, suggesting a potential physiological role in regulating gamete release in response to detection of environmental cues [48]. Therefore, it would be interesting to investigate the anatomical patterns of RGP expression in COTS. Evidence that RGP regulates gamete release in COTS has been reported previously with the discovery that $P$. pectinifera RGP (COTS RGPa) stimulates oocyte maturation and release from COTS ovarian tissue in vitro [11]. Further studies are now required to investigate the bioactivity of the RGPb protein that we have identified here based on analysis of COTS genomic and transcriptomic sequence data.

\section{Conclusions}

Neuropeptides derived from a total of 48 neuropeptide precursors have been discovered through this the first exploration of the COTS neuropeptidome. A major task now will be to determine the exact function, through targeted bioassay approaches, of COTS neuropeptides identified in this study. Since neuropeptides regulate key biological processes and behaviour, the COTS neuropeptides identified here may provide insight into the design of selective, potent and environmentally safe compounds to control COTS outbreaks. While the neuropeptides may not themselves be useful as control agents, they may assist in the discovery of neuropeptide receptors that could be targeted. Of particular interest are 10 of the 48 neuropeptide precursors that are novel and may be unique to starfish and therefore attractive for targeted COTS biocontrol strategies. 


\section{Acknowledgments}

This study acknowledges the aquarists and facility staff at the Australian Institute of Marine Science for assistance with animal housing and care. We gratefully thank Dr Alun Jones (Institute for Molecular Bioscience, the University of Queensland) for advice and assistance with the LC-MS/MS. This research was undertaken with the assistance of resources from the National Computational Infrastructure (NCI), which is supported by the Australian Government. This study was supported by funds from the Australian federal government Department of the Environment Reef Rescue 'Caring for Country' program for funding the 'The Crown-of-Thorns secretome: Towards a control technology' project (M. R. H., S. C.). M.R.E. was supported by grants from the BBSRC (BB/M001644/1) and Leverhulme Trust (RPG-2013-351).

\section{Author contributions}

MKS carried out the sample collection, laboratory work for the molecular biology and chemistry components, data analysis, bioinformatics, sequence alignments, schematic and figure preparations and manuscript draft; TW carried out the proteomic and mass spectrometry laboratory work and analysis; SS assisted with bioinformatics analysis; CAM assisted with the drafting of the manuscript; AE was involved in the design of the study and drafting of the manuscript; $\mathrm{MZ}$ assisted with the bioinformatics components of the study and generation of heatmap imagery; MLR assisted with assembly of the transcriptomes; MRE provided assistance with data analysis and drafting of the manuscript; MRH assisted with the study design, sample collection and animal care and with drafting of the manuscript; SFC assisted with laboratory 
work, data analysis, figure preparation and manuscript drafting. All authors gave final approval for publication.

\section{References}

[1] J. Hunt, Great Barrier Reef coral loss and crown-of-thorns starfish Australian Canegrower 18 (2013) 12-13.

[2] G. Kenyon, The starfish eating the reef [online]. Wildlife Australia 51(3) (2014) 30-32.

[3] R.G. Coles, M.A. Rasheed, L.J. McKenzie, A. Grech, P.H. York, M. Sheaves, S. McKenna, C. Bryant, The Great Barrier Reef World Heritage Area seagrasses: Managing this iconic Australian ecosystem resource for the future, Estuarine, Coastal and Shelf Science 153 (2015) A1-A12.

[4] Great Barrier Reef Marine Park Authority, Protecting the future of the Great Barrier Reef: Great Barrier Reef region strategic assessment, (2014).

[5] C. Vogler, J. Benzie, P.H. Barber, M.V. Erdmann, Ambariyanto, C. Sheppard, K. Tenggardjaja, K. Gérard, G. Wörheide, Phylogeography of the Crown-of-Thorns Starfish in the Indian Ocean, PLOS ONE 7(8) (2012) e43499.

[6] V.S. Mashanov, O.R. Zueva, T. Heinzeller, I.Y. Dolmatov, Ultrastructure of the circumoral nerve ring and the radial nerve cords in holothurians (Echinodermata), Zoomorphology 125(1) (2006) 27-38.

[7] J.L.S. Cobb, The neurobiology of the ectoneural/hyponeural synaptic connection in an echinoderm., The Biological Bulletin 168(3) (1985) 432-446.

[8] J.L.S. Cobb, Neurobiology of the Echinodermata, in: M.A. Ali (Ed.), Nervous Systems in Invertebrates, Springer US, Boston, MA, 1987, pp. 483-525.

[9] E.D. Ketterson, J.W. Atwell, J.W. McGlothlin, Evolution of hormones and behavior, The Princeton Guide to Evolution (2013) 161-23.

[10] G. Jékely, Global view of the evolution and diversity of metazoan neuropeptide signaling, Proceedings of the National Academy of Sciences 110(21) (2013) 8702-8707. [11] M. Mita, N. Ikeda, S. Haraguchi, K. Tsutsui, Y. Nakano, M. Nakamura, A gonadstimulating peptide of the crown-of-thorns starfish, Acanthaster planci, Invertebrate Reproduction \& Development 59(4) (2015) 212-217.

[12] A.B. Chaet, The gamete-shedding substances of starfishes: a physiological-biochemical study, American zoologist 6(2) (1966) 263-71.

[13] A.M. Chaet, R., Physiologic activity of nerve extracts, Biological Bulletin 117 (1959) 407408.

[14] M. Inoue, R. Birenheide, O. Koizumi, Y. Kobayakawa, Y. Muneoka, T. Motokawa, Localization of the neuropeptide NGIWYamide in the holothurian nervous system and its effects on muscular contraction, Proc. R. Soc. Lond. B. Biol. Sci. 266(1423) (1999) 993.

[15] S. Kato, S. Tsurumaru, M. Taga, T. Yamane, Y. Shibata, K. Ohno, A. Fujiwara, K. Yamano, M. Yoshikuni, Neuronal peptides induce oocyte maturation and gamete spawning of sea cucumber, Apostichopus japonicus, Developmental biology 326(1) (2009) 169-76.

[16] D.C. Semmens, R.E. Dane, M.R. Pancholi, S.E. Slade, J.H. Scrivens, M.R. Elphick, Discovery of a novel neurophysin-associated neuropeptide that triggers cardiac stomach contraction and retraction in starfish, Journal of Experimental Biology 216(Pt 21) (2013) 4047-53. 
[17] M.R. Elphick, S.J. Newman, M.C. Thorndyke, Distribution and action of SALMFamide neuropeptides in the starfish Asterias rubens, The Journal of Experimental Biology 198(12) (1995) 2519-2525.

[18] R. Melarange, D.J. Potton, M.C. Thorndyke, M.R. Elphick, SALMFamide neuropeptides cause relaxation and eversion of the cardiac stomach in starfish, Proceedings of the Royal Society B: Biological Sciences 266(1430) (1999) 1785-1785.

[19] M. Elphick, D. Price, T. Lee, M. Thorndyke, The SALMFAmides: A New Family of Neuropeptides Isolated from an Echinoderm, Proceedings of the Royal Society of London. Series B: Biological Sciences 243(1307) (1991) 121.

[20] C.H. Kim, E.J. Kim, H.J. Go, H.Y. Oh, M. Lin, M.R. Elphick, N.G. Park, Identification of a novel starfish neuropeptide that acts as a muscle relaxant, Journal of Neurochemistry 137(1) (2016) 33-45.

[21] E. Sodergren, G.M. Weinstock, E.H. Davidson, R.A. Cameron, R.A. Gibbs, R.C. Angerer, L.M. Angerer, M.I. Arnone, D.R. Burgess, R.D. Burke, J.A. Coffman, M. Dean, M.R. Elphick, C.A. Ettensohn, K.R. Foltz, A. Hamdoun, R.O. Hynes, W.H. Klein, W. Marzluff, D.R. McClay, R.L. Morris, A. Mushegian, J.P. Rast, L.C. Smith, M.C. Thorndyke, V.D. Vacquier, G.M. Wessel, G. Wray, L. Zhang, C.G. Elsik, O. Ermolaeva, W. Hlavina, G. Hofmann, P. Kitts, M.J. Landrum, A.J. Mackey, D. Maglott, G. Panopoulou, A.J. Poustka, K. Pruitt, V. Sapojnikov, X. Song, A. Souvorov, V. Solovyev, Z. Wei, C.A. Whittaker, K. Worley, K.J. Durbin, Y. Shen, O. Fedrigo, D. Garfield, R. Haygood, A. Primus, R. Satija, T. Severson, M.L. Gonzalez-Garay, A.R. Jackson, A. Milosavljevic, M. Tong, C.E. Killian, B.T. Livingston, F.H. Wilt, N. Adams, R. Belle, S. Carbonneau, R. Cheung, P. Cormier, B. Cosson, J. Croce, A. Fernandez-Guerra, A.M. Geneviere, M. Goel, H. Kelkar, J. Morales, O. Mulner-Lorillon, A.J. Robertson, J.V. Goldstone, B. Cole, D. Epel, B. Gold, M.E. Hahn, M. Howard-Ashby, M. Scally, J.J. Stegeman, E.L. Allgood, J. Cool, K.M. Judkins, S.S. McCafferty, A.M. Musante, R.A. Obar, A.P. Rawson, B.J. Rossetti, I.R. Gibbons, M.P. Hoffman, A. Leone, S. Istrail, S.C. Materna, M.P. Samanta, V. Stolc, W. Tongprasit, Q. Tu, K.F. Bergeron, B.P. Brandhorst, J. Whittle, K. Berney, D.J. Bottjer, C. Calestani, K. Peterson, E. Chow, Q.A. Yuan, E. Elhaik, D. Graur, J.T. Reese, I. Bosdet, S. Heesun, M.A. Marra, J. Schein, M.K. Anderson, V. Brockton, K.M. Buckley, A.H. Cohen, S.D. Fugmann, T. Hibino, M. Loza-Coll, A.J. Majeske, C. Messier, S.V. Nair, Z. Pancer, D.P. Terwilliger, C. Agca, E. Arboleda, N. Chen, A.M. Churcher, F. Hallbook, G.W. Humphrey, M.M. Idris, T. Kiyama, S. Liang, D. Mellott, X. Mu, G. Murray, R.P. Olinski, F. Raible, M. Rowe, J.S. Taylor, K. Tessmar-Raible, D. Wang, K.H. Wilson, S. Yaguchi, T. Gaasterland, B.E. Galindo, H.J. Gunaratne, C. Juliano, M. Kinukawa, G.W. Moy, A.T. Neill, M. Nomura, M. Raisch, A. Reade, M.M. Roux, J.L. Song, Y.H. Su, I.K. Townley, E. Voronina, J.L. Wong, G. Amore, M. Branno, E.R. Brown, V. Cavalieri, V. Duboc, L. Duloquin, C. Flytzanis, C. Gache, F. Lapraz, T. Lepage, A. Locascio, P. Martinez, G. Matassi, V. Matranga, R. Range, F. Rizzo, E. Rottinger, W. Beane, C. Bradham, C. Byrum, T. Glenn, S. Hussain, G. Manning, E. Miranda, R. Thomason, K. Walton, A. Wikramanayke, S.Y. Wu, R. Xu, C.T. Brown, L. Chen, R.F. Gray, P.Y. Lee, J. Nam, P. Oliveri, J. Smith, D. Muzny, S. Bell, J. Chacko, A. Cree, S. Curry, C. Davis, H. Dinh, S. Dugan-Rocha, J. Fowler, R. Gill, C. Hamilton, J. Hernandez, S. Hines, J. Hume, L. Jackson, A. Jolivet, C. Kovar, S. Lee, L. Lewis, G. Miner, M. Morgan, L.V. Nazareth, G. Okwuonu, D. Parker, L.L. Pu, R. Thorn, R. Wright, The genome of the sea urchin Strongylocentrotus purpuratus, Science (New York, N.Y.) 314(5801) (2006) 941-52. 
[22] R.D. Burke, L.M. Angerer, M.R. Elphick, G.W. Humphrey, S. Yaguchi, T. Kiyama, S. Liang, X. Mu, C. Agca, W.H. Klein, B.P. Brandhorst, M. Rowe, K. Wilson, A.M. Churcher, J.S. Taylor, N. Chen, G. Murray, D. Wang, D. Mellott, R. Olinski, F. Hallböök, M.C. Thorndyke, A genomic view of the sea urchin nervous system, Developmental Biology 300(1) (2006) 434-460.

[23] M.R. Elphick, M.L. Rowe, NGFFFamide and echinotocin: structurally unrelated myoactive neuropeptides derived from neurophysin-containing precursors in sea urchins, Journal of Experimental Biology 212(Pt 8) (2009) 1067-77.

[24] M.L. Rowe, S. Achhala, M.R. Elphick, Neuropeptides and polypeptide hormones in echinoderms: new insights from analysis of the transcriptome of the sea cucumber Apostichopus japonicus, General Comparative Endocrinology 197 (2014) 43-55.

[25] D.C. Semmens, O. Mirabeau, I. Moghul, M.R. Pancholi, Y. Wurm, M.R. Elphick, Transcriptomic identification of starfish neuropeptide precursors yields new insights into neuropeptide evolution, Open Biology 6(2) (2016).

[26] M.R. Hall, K.M. Kocot, K.W. Baughman, S.L. Fernandez-Valverde, M.E.A. Gauthier, W.L. Hatleberg, A. Krishnan, C. McDougall, C.A. Motti, E. Shoguchi, T. Wang, X. Xiang, M. Zhao, U. Bose, C. Shinzato, K. Hisata, M. Fujie, M. Kanda, S.F. Cummins, N. Satoh, S.M. Degnan, B.M. Degnan, The crown-of-thorns starfish genome as a guide for biocontrol of this coral reef pest, Nature 544(7649) (2017) 231-234.

[27] M.L. Rowe, M.R. Elphick, The neuropeptide transcriptome of a model echinoderm, the sea urchin Strongylocentrotus purpuratus, General Comparative Endocrinology 179(3) (2012) 331-44.

[28] T.N. Petersen, S. Brunak, G. von Heijne, H. Nielsen, SignalP 4.0: discriminating signal peptides from transmembrane regions, Nature methods 8(10) (2011) 785-6.

[29] A. Krogh, B. Larsson, G. von Heijne, E.L. Sonnhammer, Predicting transmembrane protein topology with a hidden Markov model: application to complete genomes, Journal of molecular biology 305(3) (2001) 567-80.

[30] B.R. Southey, S.L. Rodriguez-Zas, J.V. Sweedler, Characterization of the prohormone complement in cattle using genomic libraries and cleavage prediction approaches, BMC genomics 10 (2009) 228.

[31] G. Gimpl, F. Fahrenholz, The oxytocin receptor system: structure, function, and regulation, Physiological reviews 81(2) (2001) 629-83.

[32] S. Kumar, G. Stecher, K. Tamura, MEGA7: Molecular Evolutionary Genetics Analysis Version 7.0 for Bigger Datasets, Molecular Biology and Evolution 33(7) (2016) 1870-1874. [33] E. Beitz, TeXshade: shading and labeling of multiple sequence alignments using LaTeX2e, Bioinformatics 16(2) (2000) 135-139.

[34] M.R. Elphick, NG peptides: a novel family of neurophysin-associated neuropeptides, Gene 458(1-2) (2010) 20-6.

[35] R.A. Cameron, M. Samanta, A. Yuan, D. He, E. Davidson, SpBase: the sea urchin genome database and web site, Nucleic Acids Research 37(Database issue) (2009) D750-4.

[36] D.C. Semmens, I. Beets, M.L. Rowe, L.M. Blowes, P. Oliveri, M.R. Elphick, Discovery of sea urchin NGFFFamide receptor unites a bilaterian neuropeptide family, Open Biology 5(4) (2015).

[37] S. Tian, M. Zandawala, I. Beets, E. Baytemur, S.E. Slade, J.H. Scrivens, M.R. Elphick, Urbilaterian origin of paralogous $\mathrm{GnRH}$ and corazonin neuropeptide signalling pathways, Scientific Reports 6 (2016). 
[38] M.R. Elphick, R. Melarange, Neural control of muscle relaxation in echinoderms, Journal of Experimental Biology 204(5) (2001) 875.

[39] M.R. Elphick, SALMFamide salmagundi: The biology of a neuropeptide family in echinoderms, General and comparative endocrinology 205 (2014) 23-35.

[40] M. Mita, M. Yoshikuni, K. Ohno, Y. Shibata, B. Paul-Prasanth, S. Pitchayawasin, M. Isobe, $Y$. Nagahama, A relaxin-like peptide purified from radial nerves induces oocyte maturation and ovulation in the starfish, Asterina pectinifera, Proceedings of the National Academy of Sciences 106(23) (2009) 9507-9512.

[41] M. Mita, M. Daiya, S. Haraguchi, K. Tsutsui, Y. Nagahama, A new relaxin-like gonadstimulating peptide identified in the starfish Asterias amurensis, General and Comparative Endocrinology 222 (2015) 144-149.

[42] M. Lin, M. Mita, M. Egertová, C.G. Zampronio, A.M. Jones, M.R. Elphick, Cellular localization of relaxin-like gonad-stimulating peptide expression in Asterias rubens: New insights into neurohormonal control of spawning in starfish, Journal of Comparative Neurology 525(7) (2017) 1599-1617.

[43] H. Shirai, H. Kanatani, S. Taguchi, 1-methyladenine biosynthesis in starfish ovary: action of gonad-stimulating hormone in methylation, Science (New York, N.Y.) 175(4028) (1972) 1366-8.

[44] T. Kishimoto, A primer on meiotic resumption in starfish oocytes: the proposed signaling pathway triggered by maturation-inducing hormone, Molecular reproduction and development 78(10-11) (2011) 704-7.

[45] M. Mita, Release of relaxin-like gonad-stimulating substance from starfish radial nerves by lonomycin, Zoological science 30(7) (2013) 602-6.

[46] M. Yoshikuni, K. Ishikawa, M. Isobe, T. Goto, Y. Nagahama, Characterization of 1methyladenine binding in starfish oocyte cortices, Proceedings of the National Academy of Sciences of the United States of America 85(6) (1988) 1874-7.

[47] T.E. Schroeder, Microfilament-mediated surface change in starfish oocytes in response to 1-methyladenine: implications for identifying the pathway and receptor sites for maturation-inducing hormones, The Journal of cell biology 90(2) (1981) 362-71.

[48] N.J. Emery, Cognitive ornithology: The evolution of avian intelligence, Philos. Trans. R. Soc. Lond. B Biol. Sci. 361(1465) (2006) 23-43.

\section{Figures}

Figure 1. The Crown-of-Thorns Starfish (COTS) radial nerve and spectral profile of a radial nerve extract. (A) Image of COTS (inset) from which an arm was removed (green box) and dissected to reveal the location of the radial nerve along the length of the arm. TF, tube 
foot. (B) Representative reverse phase high performance liquid chromatography (RP-HPLC) chromatogram measuring UV absorbance $(210 \mathrm{~nm})$ of radial nerve extract.

Figure 2. Heat-map demonstrating relative expression of neuropeptide precursor genes in Crown-of-Thorns Starfish (COTS) radial nerve and somatic tissues. Relative expression (Z-score) and distribution of 44 of the 48 identified COTS neuropeptide precursors in transcriptomes of COTS tissues - male radial nerve, female radial nerve, sensory tentacles, spine, mouth, podia, oocyte and testis. Scaled Z-score log -3 (light yellow) to log 3 (dark red).

Figure 3. Schematics of selected Crown-of-Thorns Starfish (COTS) neuropeptide precursors showing their structural organisation. Signal sequence (yellow), predicted mature bioactive peptide regions (purple), sites of amidation (green) and cleavage sites (red).

Figure 4. Comparative analysis of Crown-of-Thorns Starfish (COTS) relaxin-like gonadstimulating peptide (RGP) with related peptides and precursors in other starfish. A) Alignment of COTS (Acanthaster planci) RGPb neuropeptide precursor with other starfish RGP precursors. Sequence logo shows regions of conservation within the A and B chains, and blue shading indicates amino acid conservation. (B) Phylogenetic analysis of RGP relationships and schematic representation of RGP neuropeptide precursor. Asterisk indicates COTS precursor identified in this study. Scale bar represents amino acid substitutions. Accession numbers for the RGP precursor proteins are: A. planci (a) [BAQ59100.1], C. seminregularis [BAS04358.1], A. amurensis [BAR40315.1], A. japonica [BAU20369.1 ], P. miniata [BAR90703.1], P. pectinifera [BAQ35470.1], C. acurispina [BAU68093.1].

Figure 5. Sequences of novel Crown-of-Thorns Starfish (COTS) putative neuropeptide precursors ApNP33, ApNP34 and ApNP35. Precursor sequences show signal peptide (purple), putative cleavage sites (red), cysteines (underline) and grey highlights regions with MS peptide matches. Asterisk indicates a stop codon.

Table 1. Summary of Crown-of-Thorns Starfish (A. planci) neuropeptide precursors, mass spectral (MS) support in radial nerve (RN) and tissue expression. Shaded cells indicate 
positive identification. AA number, amino acid number. Signal size, size of signal peptide in amino acids.

\begin{tabular}{|c|c|c|c|c|c|c|c|c|c|c|c|c|c|}
\hline & & & & \multicolumn{10}{|c|}{ TISSUES } \\
\hline $\begin{array}{l}2 \\
\text { ב⿱ } \\
\text { בై }\end{array}$ & 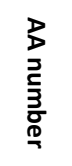 & 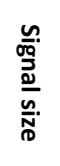 & 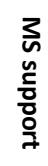 & $\begin{array}{l}\text { ग } \\
\stackrel{3}{3} \\
\frac{0}{0} \\
\text { गु }\end{array}$ & $\begin{array}{l}3 \\
\frac{3}{0} \\
\frac{7}{2}\end{array}$ & 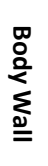 & 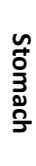 & 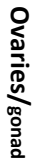 & $\frac{\text { ֻ }}{\vec{D}}$ & 怘 & $\frac{3}{0}$ & 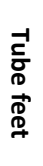 & 을 \\
\hline AN peptide precursor protein (ApANPP) & 219 & 29 & + & + & + & + & + & + & + & + & + & + & + \\
\hline ApNP11-like & 102 & 22 & & + & + & + & + & + & + & + & + & + & + \\
\hline ApNP15a-like & 107 & 21 & + & + & + & + & + & + & + & + & + & + & + \\
\hline ApNp15b-like & 105 & 24 & + & + & + & + & + & + & + & + & + & + & + \\
\hline ApNp18-like & 102 & 27 & + & + & + & + & + & + & + & + & + & + & + \\
\hline ApNp22-like & 121 & 21 & & + & + & + & + & & + & & & + & + \\
\hline ApNp23-like & 139 & & & + & + & + & + & & + & & + & + & + \\
\hline ApNp25-like & 102 & 31 & & + & + & + & + & & + & & + & + & + \\
\hline ApNP26 & 122 & 64 & + & + & + & + & + & + & + & & + & + & + \\
\hline APNP27 & 102 & 21 & + & & + & & & + & + & & + & & \\
\hline ApNP28 & 116 & 29 & & + & + & & + & + & + & + & + & & \\
\hline ApNP29 & 89 & 21 & + & + & + & + & + & + & + & + & + & & \\
\hline ApNP30 & 147 & 37 & + & + & + & + & & + & + & + & & & \\
\hline ApNP31 & 109 & 23 & + & + & + & + & + & + & + & & & + & + \\
\hline ApNP32 & 187 & 21 & + & + & + & + & + & + & + & & & & \\
\hline ApNP33 & 104 & 20 & + & + & + & + & + & + & + & + & & + & + \\
\hline ApNP34 & 117 & 23 & + & + & + & + & + & + & + & & & + & + \\
\hline ApNP35 & 245 & 23 & + & + & + & + & + & + & + & + & + & + & + \\
\hline Bombyxin related peptide & 131 & & & + & + & + & + & + & + & & + & & \\
\hline Buriscon-Alpha_1 & 139 & 34 & & + & + & + & + & + & + & + & & + & + \\
\hline Buriscon-Alpha_2 & 137 & 23 & & + & + & + & + & + & + & + & + & + & + \\
\hline Buriscon-Alpha_3 & 75 & & & + & + & & + & + & + & + & & + & + \\
\hline Bursicon-beta & 141 & 29 & & + & + & & + & + & + & + & & + & + \\
\hline Calcitonin precursor & 123 & & & & & + & & & & & & & \\
\hline Cholecystokinin-type precursor (ApCCK) & 158 & 22 & + & + & + & + & + & & + & & + & + & + \\
\hline Corazonin-type precursor (ApCRZP) & 100 & 23 & + & + & + & & + & & + & & + & + & + \\
\hline Glycoprotein Hormone (GPH)-alpha-2 & 127 & 24 & & + & + & & + & & + & & & & \\
\hline Glycoprotein Hormone (GPH)-beta-5 (1) & 136 & 24 & & + & + & & + & & + & + & & & + \\
\hline Glycoprotein Hormone (GPH)-beta-5 (2) & 131 & 30 & & + & + & & + & & + & + & & & + \\
\hline Glycoprotein Hormone (GPH)-beta-5 (3) & 102 & 21 & & + & + & & + & & + & + & & & + \\
\hline $\begin{array}{l}\text { Gonadotropin-releasing hormone type } \\
\text { precursor (ApGnRHP) }\end{array}$ & 122 & 27 & & + & + & + & + & + & + & & & + & + \\
\hline Insulin-type precursor & 136 & & & + & + & + & + & + & + & + & + & + & + \\
\hline
\end{tabular}




\begin{tabular}{|c|c|c|c|c|c|c|c|c|c|c|c|c|c|}
\hline Kisspeptin (KP)-type precursor & 374 & 24 & + & & + & + & + & + & + & + & + & + & + \\
\hline Luqin-type precursor & 316 & & & + & + & + & + & + & + & + & + & + & + \\
\hline $\begin{array}{l}\text { Melanin-concentrating hormone-type } \\
\text { precursor }\end{array}$ & 101 & 24 & + & + & + & & & & + & & & & \\
\hline NGFFYamide & 248 & & & + & + & + & + & + & + & & & + & + \\
\hline Orexin type precursor 1 & 107 & 20 & & + & + & & + & + & + & + & & + & + \\
\hline Orexin type precursor 2 & 96 & 24 & + & + & + & & + & + & + & + & & + & + \\
\hline Pedal peptide-type precursor (ApPPLNP) & 337 & & + & + & + & + & + & + & + & + & & + & + \\
\hline $\begin{array}{l}\text { Relaxin Like gonadotropic peptide } \\
\text { precursor (ApRGPP) }\end{array}$ & 124 & 36 & & + & + & & & + & + & & & & + \\
\hline SALMFamide (F-type) precursor & 266 & 27 & + & + & + & + & + & + & + & + & + & + & + \\
\hline SALMFamide (L-type) precursor & 198 & & + & + & + & + & + & + & + & + & + & + & + \\
\hline Secretogranin 7B2 like protein precursor & 244 & 18 & + & + & + & + & + & + & + & + & + & + & + \\
\hline Somatostatin- type precursor & 133 & 24 & & + & + & & + & + & + & & + & + & + \\
\hline $\begin{array}{l}\text { Starfish Myorelaxant peptide precursor } \\
\text { (SMP) }\end{array}$ & 406 & & + & + & + & + & + & + & + & + & & + & + \\
\hline Tachykinin-type precursor & 185 & 31 & + & + & + & + & + & & + & + & + & + & + \\
\hline $\begin{array}{l}\text { Thyrotropin-releasing hormone peptide } \\
\text { (ApTRH) }\end{array}$ & 221 & 25 & + & + & + & + & + & & + & & & + & + \\
\hline Vasopressin/Oxytocin (Asterotocin) & 188 & 21 & & + & + & + & + & + & + & + & & + & + \\
\hline
\end{tabular}

\section{Supplementary files}

Figure S1. Workflow for identification of neuropeptides in the Crown-of-Thorns starfish, Acanthaster planci.

File S1. Neuropeptide precursors and mass spectral matching peptides identified in the Crown-of-Thorns Starfish, Acanthaster planci. Neuropeptide precursors are shown annotated signal peptide (purple), cleavage sites (red), predicted bioactive mature peptide regions if known (blue), mass spectrometry peptide matches (blue underline bar) and cysteine residues (underlined). Stop codons are indicated by *.

File S2. Patiria miniata homologs of $\mathbf{1 0}$ novel neuropeptide precursors discovered in the Crown-of-Thorns Starfish, Acanthaster planci. A planci neuropeptide precursors; ApNP26 through ApNP35, with respective homologous proteins identified by analysis of $P$. miniata genome data with $\mathrm{E}$ value significance $<10^{-3}$ (www.echinobase.org). 


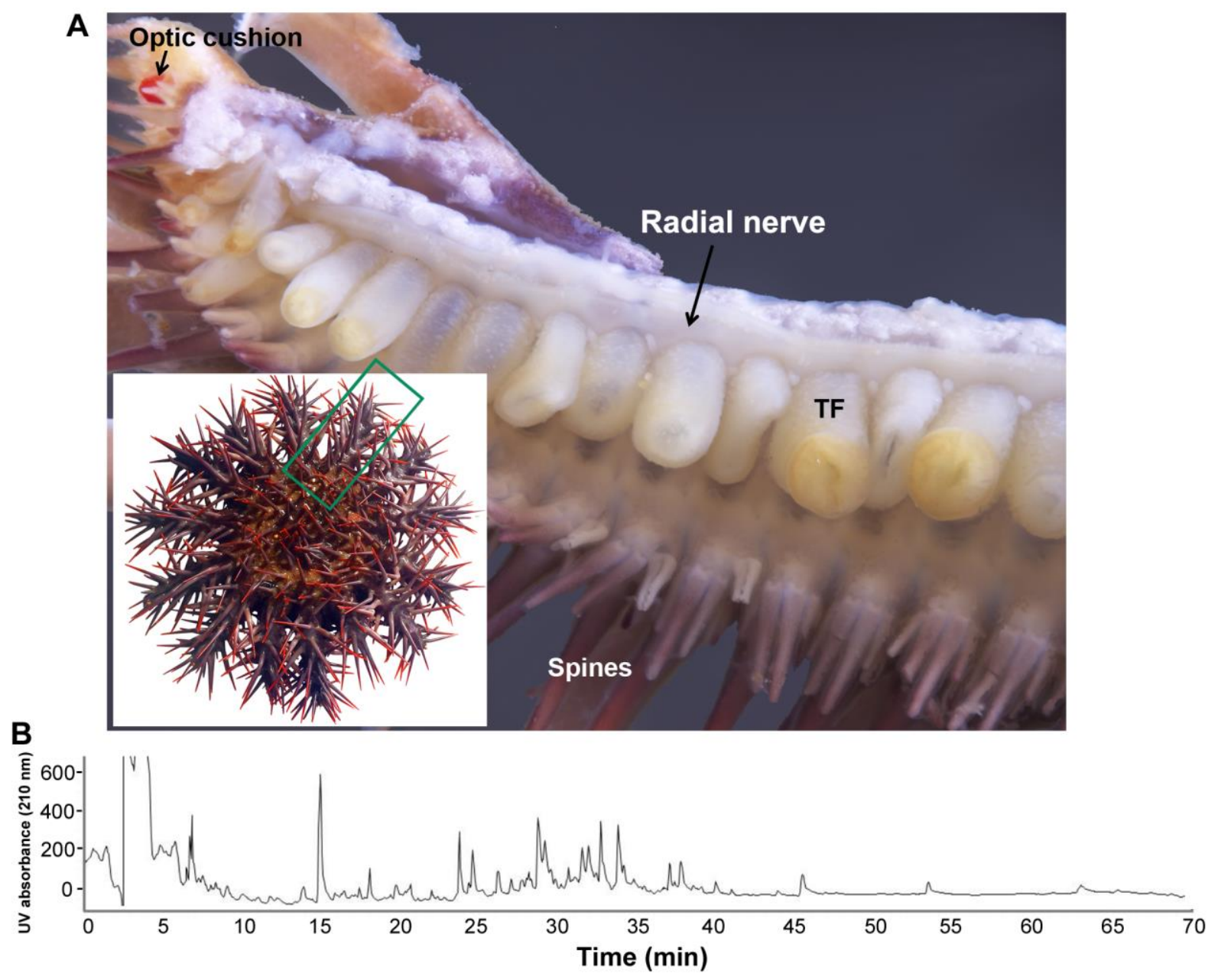

Figure 1. 


\section{Neuropeptides}
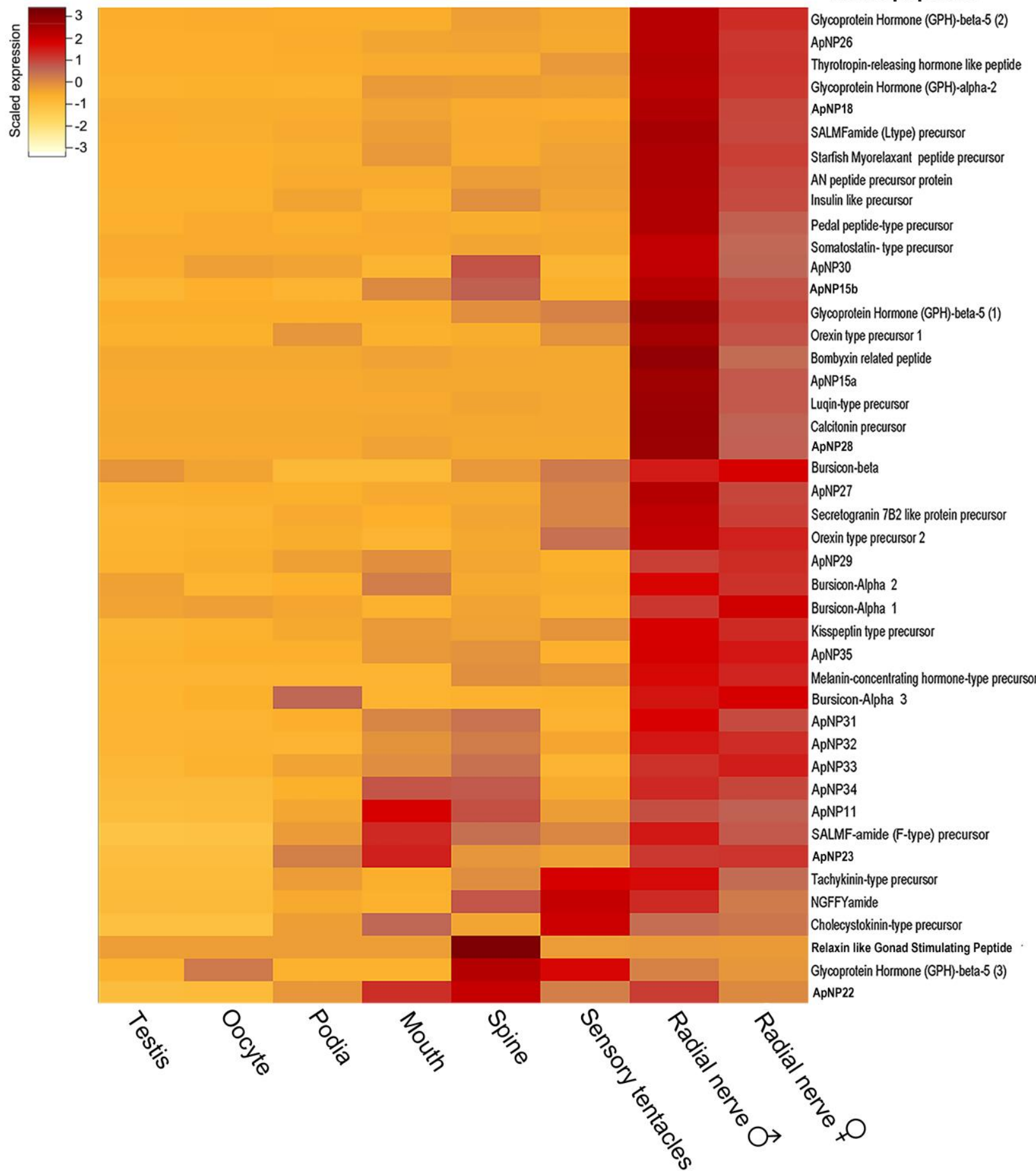

Figure 2. 
Relaxin-like Gonad Stimulating Peptide

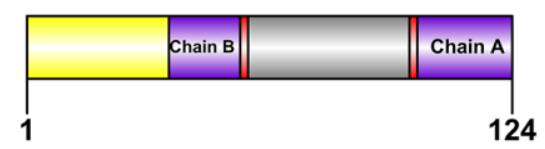

NGFFYamide

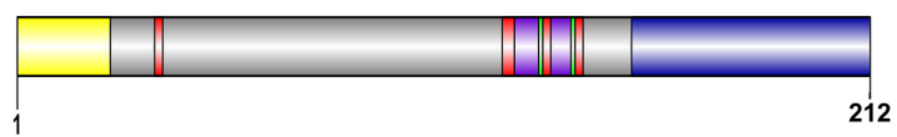

Asterotocin

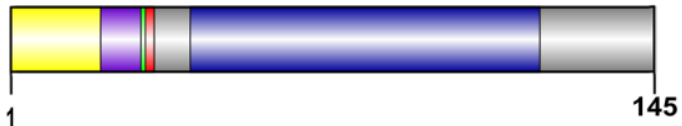

L-type SALMFamide

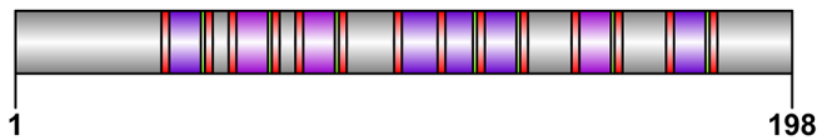

F-type SALMFamide

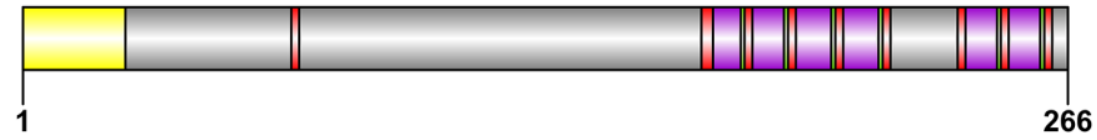

Starfish Myorelaxant Peptide (SMP)

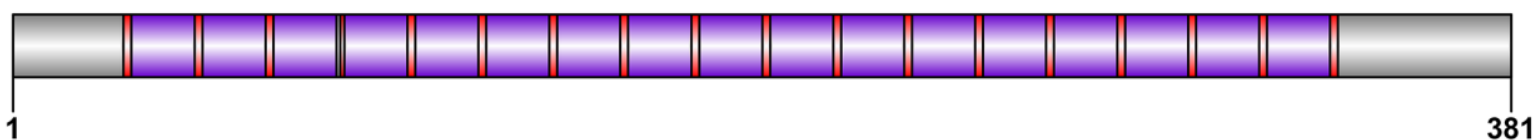

Figure 3. 
A

Acanthaster planci b Acanthaster plancia

Certonardoa semiregularis

Asterias amurensis

Aphelasterias japonica

Patiria miniata

Patiria pectinifera

Coscinasterias acurispina
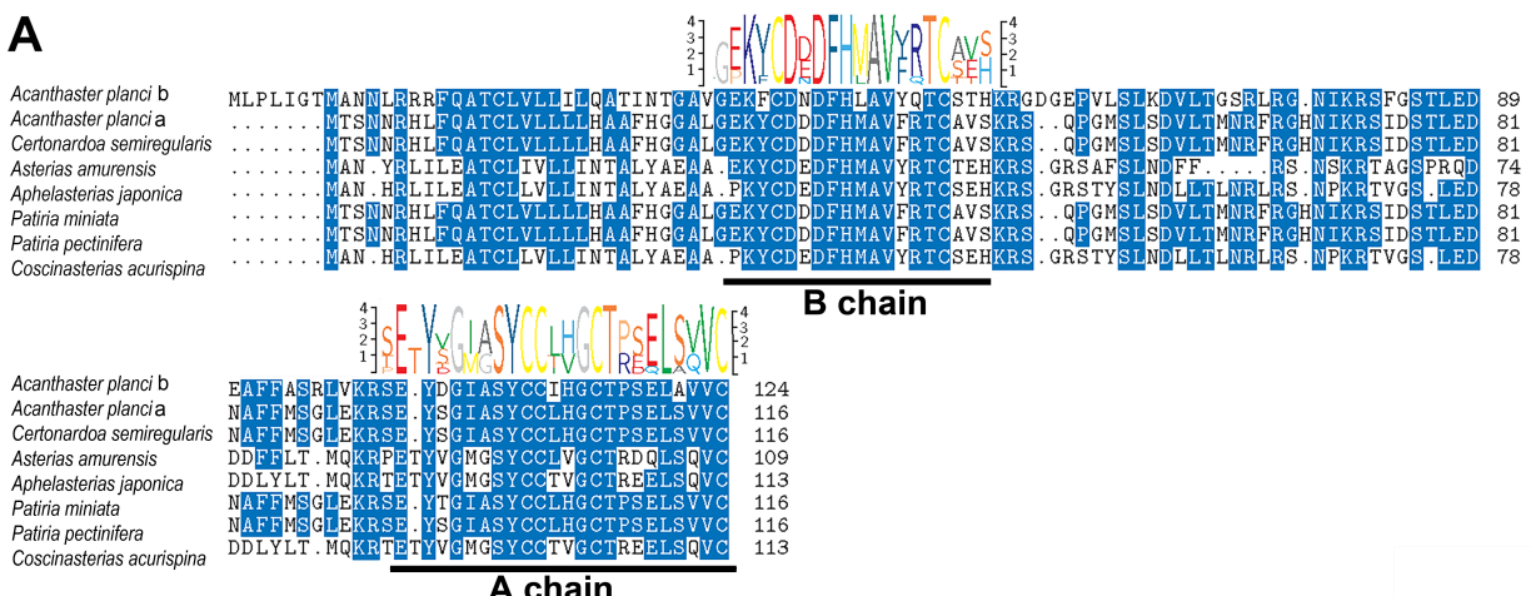

B chain

Coscinasterias acurispin

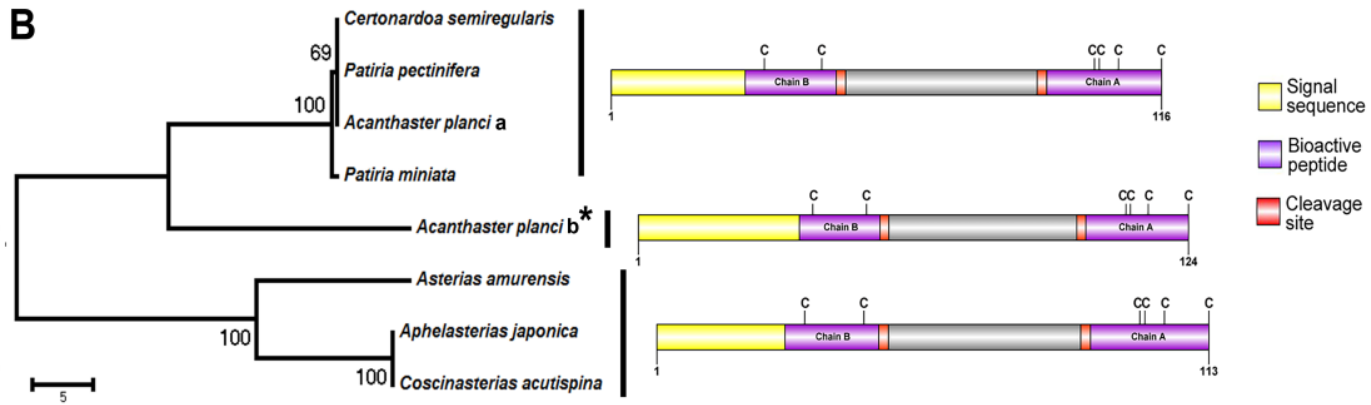

Figure 4.

ApNP33

MRYIAVALLLTILLFDVVVGDGVKAQAPDKHSPAVADSRARRAVPHAGLINPADLGMRLKSRRSD PFRRAPRMKRYRRMVEDPEMYKRGLPGGKQIRVKKASKA

\section{ApNP34}

MNLDLRCLSAGLVLLVILGVSWAVPLDLYDPDEWHQNEAQEEVKRDRWTYPAVPPRETRGRKN WRSNPYKMLNLVDDSVKTFDSRIMQAVLPIHRYYFVVVNASIKLFMYCSCYIQP*

\section{ApNP35}

MNSLCHVLVLSAAFCLFLALTSGYPLQQAGNALREDLMERRSSPQRLTVDDLLDFLNERYQESPE NEESARSFFSNFFVRFVVMSHD*

\section{Figure 5.}




\section{AN peptide Precursor Protein (ApANPP)}

MGSIPMARFEVMLLLMSVLVAVTVLQCRADEENTADEDQVKQVLQEIYDEPDEDKRANRYRTLNRRPGNRRVIKSDPAMQEEEG EEANAEEKRGNRFRTVGGRPRNRMMRVTKSDPEVESGENLEANDEEKRANRFRTVGGRPRNRMMRVTKSDPEAEGAQDALE ANEEKRANMYRSSGRSRMRGGRRRLVLSYVAFITISLDGSATRVIRLTYSDEKG*

\section{ApNP11}

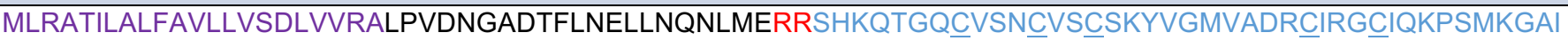
NNAEVDAWTACEKFLYR

\section{ApNP15a}

MCFCALALLFEAVIALPYADADDEFDARDMAKRVVDILSPASHHLDKRASSLCPMDCEFSCFFFIRDLTPDPCVKGCQQRRHMVGDA SYSYDRKMWNRCAQYLQRPLAR*

\section{ApNp15b}

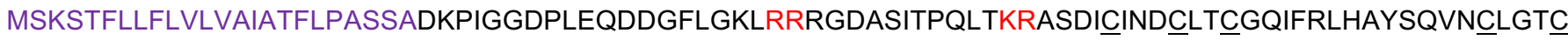
RMFPSHRDPECQEHRLG

\section{ApNp18}

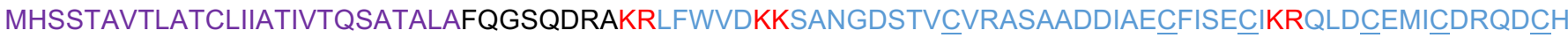
SLㅁQTKKLGㅡAKA므

\section{ApNp22}

MHIQAVTYLLAAAVLASLTSAGITWRTADDEHGYRMGEFYNQPYYPAAVEAVAERITTAQDADSDNILPLEQLAMRLLEANNERAA FRRDSRQLRFSPQKPNCRG GNICNQRGWKRSWDRRR 


\section{ApNp23}

MNLKGLGQ̣QGRVVSQTFGMKRAEKRFMGRETIIIMTNYILFIGLMIAMFAILATSSDEAAINDGMETPEDAEALNNFLHGLLQARVD RSWRKPㅁGNSㅌFQSAGGRGWKRNRAPFSLDGFKCIGAGㅌERGWKRTSERKR*

\section{ApNp25}

MAVVPGKTTRGLVWLLLFLVISAVCLQSCHAARRCSVKGCMVHFGKRIAPFSEEDEEPGTEYIKAQDYQEQQRQKNLQILRLVDR LLSGSMTSRNFPLDDET

\section{ApNP26}

MTWDSGKITFFRGRAIPSRGNYATGNPIQYTVWTRFKPVPQKVMSTKTFMLVVCLAYTLLLVTALPLDYPSDENNAFLRRLRSNK

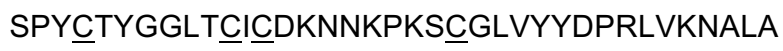

\section{ApNP27}

TMHRFIALCLALLVLAATSLAFPAQLEYLLDEDPDEQVAKRDTDEDAMYRVQRSRDSCSSINCIACGGSTWSTKFNTHQCEMKHㅡQTIT SPDSPKKYSSERRRYI

\section{ApNP28}

MTGTTATKMCVLLATFVVLLATLTEMANTMDLPYSEDENLPFGVMERPGGSHGAWQRRTVDILLEALTLLREEMDKPMGEDAQQ VVKKGNSHYLFWRTPVITSRSLSEESSRKRSN*

\section{ApNP29}

MASHTFLLTLSVATLLVAVLGAGYEEDTDALYQMFNDAMQKREDGGLMQYLVEKRGRGGSSRNYGRLEPVNIRDWDTATTQTG QGVTSS*

\section{ApNP30}

MAGGITLVGSYIRQVHGRGHQWSFHTLLVCLAACVLATQVMRCKKGQC彑AYSDRPIIMNTYRQHLDDLSAIAADILNDSTIVISPSYTD SQLDKLMGRMRHLDPAQMAILDDNVWNEYTQALDGWIWMCRRAPQTLGKRNFIKPLYKDSE*

\section{ApNP31}

MTCHKLLATAGLLLIFAVWTSQAINYYKQNKDTGSYSPPSSSRSRLPAKSQTGPSNALWIRTRDAPLDTLRYRVPMDRRMVPASM LFVDGNPDNMDKRLFEGLFPSNDR* 


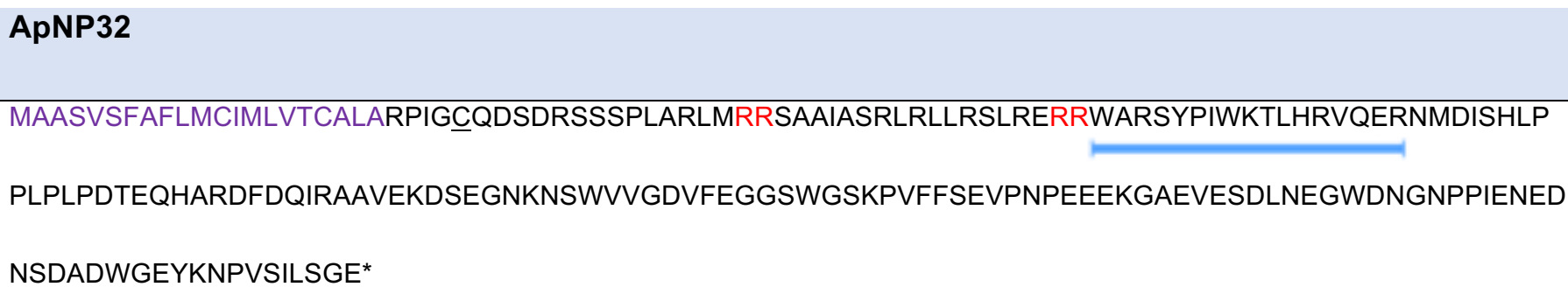

\section{ApNP33}

MRYIAVALLLTILLFDVVVGDGVKAQAPDKHSPAVADSRARRAVPHAGLINPADLGMRLKSRRSDPFRRAPRMKRYRRMVEDPE

MYKRGLPGGKQIRVKKASKA

\section{ApNP34}

MNLDLRCLLSAGLVLLVILGVSWAVPLDLYDPDEWHQNEAQEEVKRDRWTYPAVPPRETRGRKNWRSNPYKMLNLVDDSVKTFD SRIMQAVLPIHRYYFVVVNASIKLFMYㄷㅗㅡYIQP*

\section{ApNP35}

MNSLCHVLVLSAAFCLFLALTSGYPLQQAGNALREDLMERRSSPQRLTVDDLLDFLNERYQESPENEESARSFFSNFFVRFVVMS

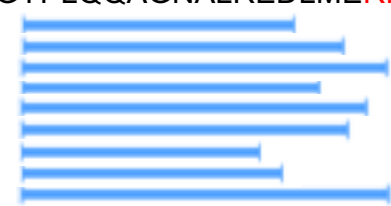

$H D^{*}$

\section{Bombyxin related peptide}

MTHSLRGTLRLPLPQARQVTVMSLVALACFVYVSADSWYCCSDVYSTVQSLCDSCYYAFFKRTNSITRPIEEPFVERKNAVDFFKR GTARGTRRGIVDECCHRQCAVSEMMLYCCEQKQREYYTFVGWLKRR*

\section{Bursicon-Alpha type-precursor 1 (ApBAP1)}

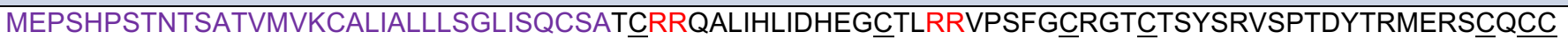

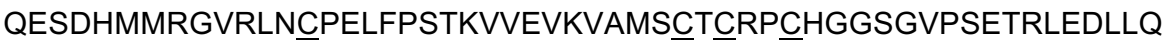

\section{Bursicon-Alpha-type precursor 2 (ApBAP2)}

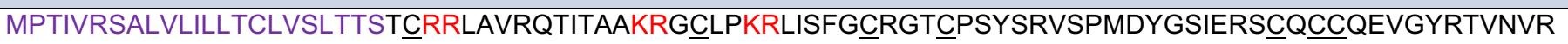

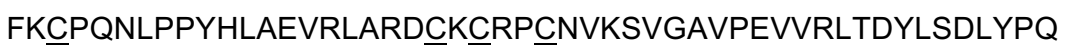

\section{Bursicon-Alpha-type precursor 3 (ApBAP3)}

SGRGWVATAALSQFCGGLETIRIEVERSFREGDTGVTRRCRGNVTLTSCEEGQCLSSVAPSVVSKDGFVKKCDCCCRE 


\section{Bursicon-beta-type precursor (ApBBP)}

MAPLNYPTAAVLLLCCALCLDLLPQKVSGGRGAPVSTㅁAAGVRSIGVQEEFLDEDRGEVVYㅁRGTATVRHㅌGGQISKSVPRLSE

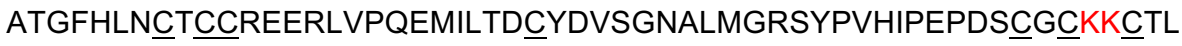

\section{Calcitonin Precursor}

MKPTAVLTLAVFCTFYTIATAASLSRGEADTVFPLKGDELRDLADKVDAYNQIVHTFSRSSEFQSMLKRSSSGCAEYFGGCAQLKL GQDALSRMLADSNSRFGSGGPGKRRRSVDAVAEDKA*

\section{Cholecystokinin-type Precursor (ApCCK)}

MNNWPSVAIATVTCLLLSPIACLPLRDVADGNDRRERLNTWLDPSDAMTNQGSKELAESAKSMLLDKPRDSGSVLDLLLALQDPN NPGDHEGFLRKQRQSKVDDYGHGMFWGKRGTWLHHDERKSGRADQQSKRAHDEYGFGLFFGKRDGADYDDFTL*

\section{Corazonin-type Precursor (ApCRZP)}

MGRNSLAATLFLAVVFGSILCSAHNTFSMSGQNRWKAGGKRSDPTVGRPQQNFLDPSSYSSDQPGENTITLREMLIDMRDY $\underline{C} F$ LLKLLDNARLAQTERK

\section{Glycoprotein Hormone (GPH)-alpha-2 (ApGPAP2)}

MRLRVTVTYLAHIAAILLFQCTAADQWNPRAGCHLVGYQKEVRIPGCHTAWVRMNACRGYCMTYSFLSDSATLERSGGTQLFTS HGSCCVITSTHDVHITLQCENNQVYKDTFKSARTCNNCALCAIP*

\section{Glycoprotein Hormone (GPH)-beta-5 precursor 1 (ApGPBP5-1)}

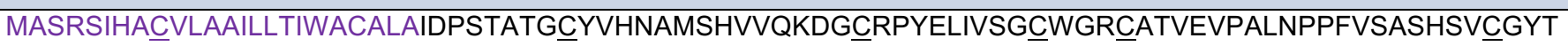
SYEERHVELPDㅁDPGVDPGYTYLHALR틑TTIDSTNTNYSYRPDYFVSKK

\section{Glycoprotein Hormone (GPH)-beta-5 precursor 2 (ApGPBP5-2)}

MTTVRLTAGQYLVVLGFLLVVVMNARPCESQDSLSCTPRQYLKYYAQKPGCRPQRVTIYGCYGRCHTSEVPRLLPPYKISDHDM CSYGETEQREIQLDDCDPGVDPTFGYIDAVSC̣VCEKCRSAFTYCQQGI

\section{Glycoprotein Hormone (GPH)-beta-5 precursor 3 (ApGPBP5-3)}

MPVNWSAVLLLHLVTATFVLSTAGGLQSPRDRDRPTRPRRGSNGGCRIREYLEHQVEVPGCRPQVIPVRGCFGQCQQTYEVPML LPPHKVSHHKMㅡSYEEVEW

\section{Gonadotropin-Releasing Hormone type Precursor (ApGnRHP)}

MAGMRLVVLATILLTLIFMGEFSRCCGQIHYKVPGWGPGGKRSSQLASSNVLRKRHWRGDSRQLEEVSTDKKHQLALLQQIAKS 


\section{Insulin like Precursor}

MSSGSIRPRTNTDFSAFVTFFAFLLAGGLSKADWVKLWNTERHVNTCNNEALLPVWDVACQQNDIRKITKRMGREFLNEWTAKNFL AGSKRRKRGLNEECCHEDLGㅁWEEVAEYㅁVMHGREKHEDGSPVRGKPGRRR*

\section{Kisspeptin (KP) -type Precursor (ApKPP)}

MEGFTKCFLLVILSVCFGSLCVLGSDDLIDHPYNELERCEEHWRLYCDRLAARASTNLGTTKGKRKQEYLTDISTRDKLERQPQKLQ ATQLQYEGLFGENVSLRVCTIGRSHRATKPPPSNKALLSDVIPRTRLASVTLRTSSGGALLATMSTPALSAKHFTRRARHTHKHPG PGVPVSIRGPTIALVGAQKDNTSAVSDKSCSAVRAKPVEALRGPIQVSHQHFAEDFCFFIICLLENDFFPLDVKLKGEGIIRHPCSGSA FPSVAYGVFTGDLTDEEEGAAVLQNLIGDLIDDVDAKNGLRQAMLGETLEQAQFEAEAKRAGCRRGRCVFRGPNPNMGSRVLPF GKREEVPANTMARRGRRPSRNRPLLPFGKRR*

\section{Luqin-(LQ) -type Precursor (ApLQP)}

MEACNNWWCVRVĆDGVTYKPDWSEVRIQQLATCCDLQRVTLPLLSSLFATCEEVGRLSGRFVLTFAAITVEVHRPRRRAGPAIFTLP DTDRILIACTTGADVVASSTGSVWPGLVRFCIWLLLTLLVAQALLGSSATADEKGRFPKFMRWGKRYSPELSSSQGLVDRRVNRIL GGLSTVIPRDILAFARVMSFIKHSALAHARHTLHRYLTILFVLGAGRSAAHREGTGRGLHAERAHGCEEFENGLAWSHGLQGGTSM SGILSRQPAENQTNPKTREFVSVIGDWKMMTIGRGVALDRLLVMEGRRTDENNVTKMEDQS

\section{Melanin-Concentrating Hormone (MCH) -type Precursor (ApMCHP)}

MRLPMLMVACLAVPCLLLAQMVSSVPILDDNNRIQAFGVGDWPVDAFGDGEYLIATDKREKARGQYCMDWIHNTWRRKSRSSV GDVLRPCLIIECPPSNKII

\section{NGFFYamide}

MGGTWIPVTVIVLVVTILVPCTRSETGSGSLSQKIRREGLEGETYWLNDVGLTDQQLRQLLANSLTGPHGSTGGPTPPSGGKPKY RLYGNRLSGTGLRLSENEDESRVDTKVTPRGSNLETRKRNGFFYGKRNGFFYGKRSVLDLDNSNECTSCGPQNSGQCVMFGT CCSYSAGGCFFLTDEALPCVTSEMSKYLAYTFFKTGNIVVNNVLP*

\section{Orexin type Precursor 1 (ApOXP1)}

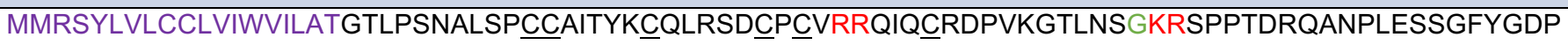
RMRASLFRRALQLANMNDGVL*

\section{Orexin type Precursor 2 (ApOXP2)}

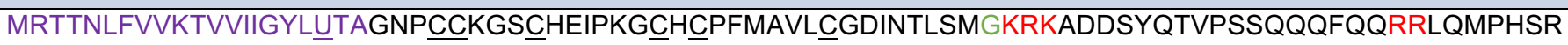
ADRRLDDDR* 


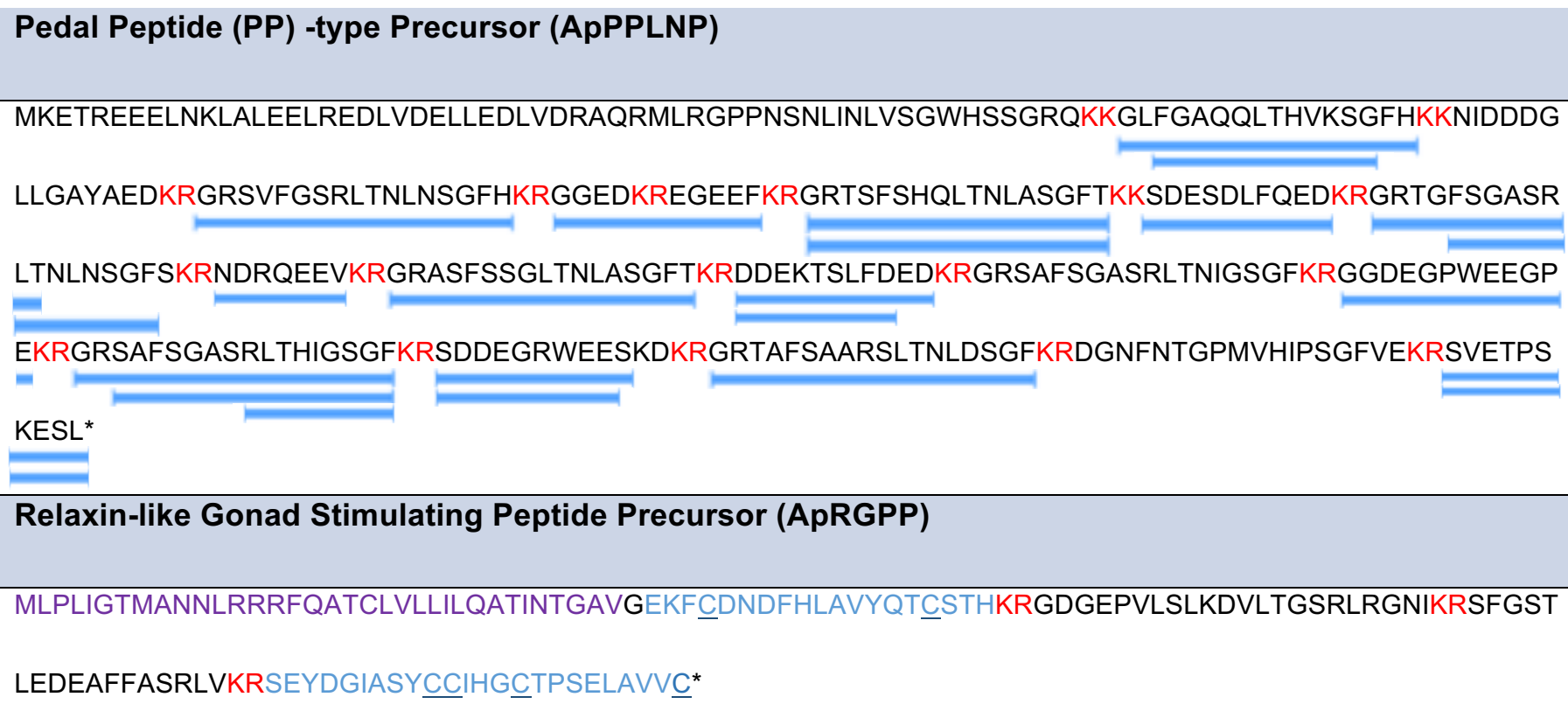

\section{SALMFamide (F-type) Precursor}

MGTTRIKMMRLIALLGIVSLLVCRSAGQDAANVEEEEDFKDLYPADRAHGFKDVNGMMDDEQHLHSATKRDVSDRQREIDLAAQ QPFYPYGRRTDVPGRPTGFIFGKRGQYFIPYQYQKRELAEVNPYSVSKRDEELTGLEEELDASKRSSGPYMSGLHSLTFGKRDA WGPEKRRDPFSYAFGKRAFGSSLTFGKRGYGMSSFDFGKRAGLDSSFTFGKRAIPDVDRYDEDALVQDDKRAFGSSLTFGKR NGLSSFTFGKRAGER*

\section{SALMFamide (L-type) Precursor} MQAEFRKTGAKRPADSPIRHSALAFGKRADDSDSEVVERRAFHSGLPFGKRTAMDRRGIHTALPFGKRTAMDRRGIHSALPFGK REEEEAERDALMERRGFNSALMFDKRIHSALPFGKRGYHSALPFGKRSGSEEEGATMDRRGYHSGLPFGKRSGIEEEGTTMDR

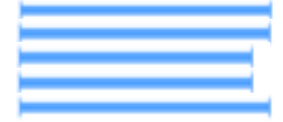

RGYHSGLPFGKREDGTDAAVSDILSQLRSDD*

\section{Secretogranin 7B2 like Protein Precursor}

MNFPLLVLSSALFLVCSAYPFSSSDRLALRSYLRDALLGDIGDAMVGPATREESAANNKLIVPPNTFVSGGAGEGKQHLGSLGKIP

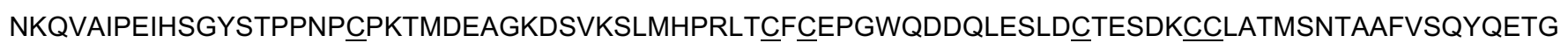
EAEEQQYMPFKRNQYIQGEKRGQLVAKKSPEIISKRSPGLRRPATKRFNPYLDDQPRIQGVVAKKSPGLSSFPAM*

\section{Somatostatin- type Precursor}

MRFCCVAAVLTTVCVLAGCLVARAAPRKGGAGEGVDPWWKRNFSPQSPEESDGDFNTNGLVQRILNRLEQRLFGSDLSEAES

WGDNQGQQLELERYRPADEEDGFIDAKEVPDDTPLTKRK $\underline{C} L G R F Q P Y A L N \underline{C}$ 
Starfish Myorelaxant Peptide Precursor (SMP)

MDGQAHEKVAEREGEKFLEEFTDDESEKGKRFGKGGAYDPLSAGFTDKRFGKGGAYDPLSAGFADKRFGKGGAYDPLSAGFT

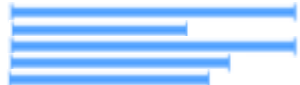

DKRFGKGGAYDPLSAGFTDKRFGKGGAYDPLSAGFTDKRFGMGGAYDPLSAGFTDKRFGKGGAYDPLSAGFADKRFGKGGAY

DPLSAGFADKRFGMGGAYDPLSAGFTDKRFGKGGAYDPLSAGFADKRFGKGGAYDPLSAGFTDKRFGMGGAYDPLSAGFTDK

RFGMGGAYDPLSAGFTDKRFGKGGAYDPLSAGFTDKRFGQGGAYDPLSAGFTDKRFGKGGAYDPLSAGFTDKRFGKGGAYDP

LSAGFTDKRSFLHGQYDPLTTGFVDGDKRGGFMRGPFRHLVTTKREPEKKDSR*

\section{Tachykinin (TK) -type Precursor (ApTKP)}

MTDRVMALNGQLTRMLLVACFLLLGVSSTRAHVYFSSGDETKPGPPEYGPGGEPKQDEPAFEDGDNEAQIPDWKERQLHAGLT

ALKHSLQSRYSAASKRSWLPGTQTGLFGKRGSHWLSPEKRQLWANQQSGLFGKREDSRDQTLPKWTVKRSAEESEFGRQRR RGVPHVFQSGGIFGKRSADDW

\section{Thyrotropin-Releasing Hormone (TRH) Peptide (ApTRHP)}

MTALRYHRGLLVTLFLTVTWASGLADLTDIVENAEVAKEVSNELEDVKAVDWEEEGDKRQYPAGAPIGLDGKRQWYTGKRQWY TGKRDAGDLQDAAALLADSGDDVKRQFYTGKRQWYTGKRSGEKEPAEEDAKRQWYTGKRQWYTGKRDDMEDEKRQWYTGK 

RQWYTGKRSDEYENNVADEAKRQWYTGKRQWYTGKRQDNEDQKRQWYTGKRQWYTGRR*

Vasopressin/Oxytocin (Asterotocin)

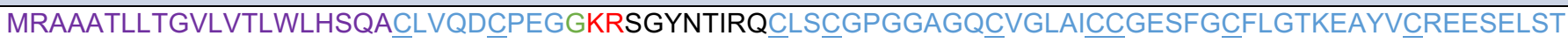

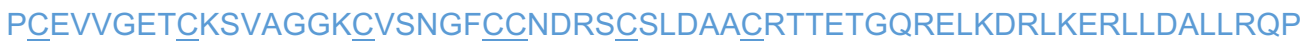




\begin{tabular}{|c|c|c|}
\hline Acanthaster planci Neuropeptide Precursor & $\begin{array}{c}\text { Patiria miniata genome1.0 } \\
\text { (www.echinobase.org) }\end{array}$ & E-value \\
\hline ApNP26 & gb|JH768864.1 & 8e-30 \\
\hline ApNP27 & gb|JH782157.1 & $6 \mathrm{e}-1$ \\
\hline ApNP28 & gb|JH769984.1 & $8 \mathrm{e}-17$ \\
\hline ApNP29 & gb|JH788549.1 & $1 \mathrm{e}-06$ \\
\hline ApNP30 & gb|JH769599.1 & $2 \mathrm{e}-25$ \\
\hline ApNP31 & gb|JH769634.1 & 2e-35 \\
\hline ApNP32 & gb|JH769105.1 & $1 \mathrm{e}-23$ \\
\hline ApNP33 & gb|JH769488.1 & $4 \mathrm{e}-23$ \\
\hline
\end{tabular}

